RESEARCH REPORT

\title{
Low job control and myocardial infarction risk in the occupational categories of Kaunas men, Lithuania
}

\author{
V Malinauskiene, T Theorell, R Grazuleviciene, R Malinauskas, A Azaraviciene
}

J Epidemiol Community Health 2004;58:131-135

See end of article for authors' affiliations

Correspondence to:

Dr V Malinauskiene,

Laboratory of

Environmental

Epidemiology, Institute of

Cardiology Kaunas

University of Medicine, Str

Sukileliu 17 Kaunas,

Lithuania, 3007;

malinav1@hotmail.com

Accepted for publication 8 September 2003

Study objective: To determine the association between adverse psychosocial characteristics at work and risk of first myocardial infarction in the occupational categories of Kaunas men, Lithuania.

Design: The analysis was based upon a case-control study among full time working men in the general population of Kaunas.

Outcome measure: First non-fatal myocardial infarction diagnosed in 2001-2002. The Swedish version of the demand-control questionnaire was used to examine the effect of job control and demands.

Setting: Kaunas, the second largest city in Lithuania, a former socialist country in a transition market economy.

Participants: Cases were 203 men 25-64 years of age with a first non-fatal myocardial infarction and controls were 287 men group randomly selected from the study base.

Main results: Low job control had a significant effect on myocardial infarction risk in the general 25-64 year old Kaunas male population $(O R=2.68 ; 95 \% \mathrm{Cl} 1.68$ to 4.28$)$ after adjustment for age and socioeconomic status. Low job control was a risk factor in the occupational categories of the increased myocardial infarction risk ( 1 st occupational category-legislators, senior officials and managers and the 8th-plant and machine operators and assemblers; $\mathrm{OR}=2.78 ; 95 \% \mathrm{Cl} 1.31$ to 5.93 and $2.72 ; 95 \% \mathrm{Cl}$ 1.56 to 4.89 , respectively, after adjustment for age and socioeconomic status). Though the adjusted odds ratio estimates were significantly high for the rest of the occupational categories (2nd-professionals, 3rd-technicians and associate professionals, and 7th-craft and related trades workers).

Conclusions: The association between low job control and first myocardial infarction risk was significant for all occupational categories of Kaunas men.

$\mathrm{T}$ here is a growing interest in the role of the psychosocial work environment for the development of coronary heart disease. A model of psychological job demands and job control was introduced by the American scientist Karasek ${ }^{1}$ and simplified in the Swedish version. ${ }^{2}$ According to this model, a high strain job is characterised by high psychological demands in combination with low job control. Although increased myocardial infarction risk was found for subjects in high strain occupations compared with subjects in other occupations in Sweden, ${ }^{3}$ many studies confirmed that low job control was stronger predictor of coronary heart disease and myocardial infarction. In a study based on the national health and nutritional examination (NHANES1) survey, high work control was associated with a low incidence of coronary heart disease, but no relation was found between job strain and coronary heart disease. ${ }^{4}$ Several studies on working men in Sweden found an increased risk of myocardial infarction in occupations characterised by low job control, ${ }^{5}$ this association remained strong after controlling for the main risk factors of coronary heart disease. ${ }^{6}$ In a prospective cohort study among British civil servants (Whitehall II study) people in the high occupational grades, who have lower coronary risk, have higher demands than the low grades. But low job control as a stronger risk factor in the work environment is associated with an increased risk of future coronary heart disease. $^{7}$ Psychological attributes, such as hostility, negative affectivity, minor psychiatric disorder, and coping affected the effect of job control very little. ${ }^{8}$

In the past decade some studies on psychosocial work environment have been performed in the countries of the previous Soviet Bloc. Low job control was consistently associated with self rated health in four post-communist countries (Poland, Czech Republic, Lithuania, and Hungary). ${ }^{9}$
In a population based case-control study in the Czech Republic low job control was strongly inversely related to myocardial infarction in men. ${ }^{10}$ The comparative cross sectional survey of 50 year old men in Vilnius, Lithuania, and Linköping, Sweden, showed that job control was significantly lower in the Lithuanian men. ${ }^{11}$

Although the role of the psychosocial factors at work in the socioeconomic gradient of myocardial infarction risk has been investigated in a number of studies in Western societies, reporting either positive ${ }^{12}{ }^{13}$ or negative associations, ${ }^{74}$ only one article has been published on the role of the occupational gradient in myocardial infarction risk in the former Soviet Union in a whole. ${ }^{15}$ And few findings about the impact of low job control in the educational gradient of the increased myocardial infarction risk in the Czech Republic ${ }^{10}$ and the higher prevalence of low job control in low social class in Lithuania $^{16}$ were reported. In a wide survey in four postcommunist countries the level of job control was not associated with education. ${ }^{9}$

The objective of our study was to evaluate the effect of low job control on first time myocardial infarction risk in the occupational categories of male population of Kaunas, Lithuania, a country in a transition market economy.

\section{METHODS}

Kaunas is the second largest city of Lithuania, a former socialist country in a transition market economy, with an area of $132 \mathrm{~km}^{2}$ and a population of about 400000 . The study base population comprised all 25-64 year old men, residing in 12 districts of the city, participating in the MONICA project. All surviving patients with a first time myocardial infarction that occurred from 1 October 2000 to 30 September 2002 were eligible for the study. The risk of 
myocardial infarction among different occupational categories was studied using a case-control study design.

\section{Identification of cases and controls}

All able bodied surviving patients with a first time myocardial infarction treated in Kaunas hospitals were considered eligible for the case-control study. The criteria for inclusion were that the participants had to be wage earners currently in employment and under 64 years of age at the time of the inclusion. A case was a person with a clinical diagnosis coded I21 of the 10th revision of International Classification of Diseases (ICD-10) in the hospital registry. In total 257 male first time myocardial infarction cases were registered, 210 $(81.7 \%)$ of these were interviewed at the hospital during their first hospitalisation week. Random controls were selected from the study base, stratified by gender and age, drawn from the population registers of the 12 districts. Controls were eligible if a clinical diagnosis of ischaemic heart disease or angina pectoris had not been recorded in their medical documents and they did not report chest pain or revealed other evidence of ischaemic heart disease during the interview. A total of 439 controls were selected, 108 (24.6\%) of them refused to participate, $15(3.4 \%)$ had chest pain complaints and history of ischaemic heart disease. In total 316 controls were included into the study (response rate $71.9 \%)$. After we excluded those with missing data on occupation and unemployed (7 cases and 29 controls), 203 cases $(78.9 \%$ of all registered) and 287 controls (65.4\%) with complete data remained (ratio 1:1.4).

\section{Data on socioeconomic status and risk factors}

Cases and controls were interviewed by trained doctors in their local hospitals, using identical standardised questionnaires, which included information on occupation, demographic, socioeconomic conditions, psychosocial factors at work, and health behavioural factors. Data on history of raised arterial blood pressure, diagnosed by a doctor, were taken from records, and the subjects underwent anthropometric measurements, such as height and weight. Education was categorised into eight or less years of schooling, secondary, and university. The International Standard Classification of Occupations as previously described ${ }^{15}$ was used to classify occupations into 10 occupational categories. The last occupation in full time employment for at least one year has been coded. Adjustment for socioeconomic status has been performed when comparing the lst occupational category with the $2 \mathrm{nd}$, 3rd, 4th, 6th and, respectively, the 2nd and the 3rd occupational categories with the rest of the white collar occupations, and comparing the 8th occupational category with the 0 th, 5th, 6th, 7th, and 9th and, respectively, the 7th occupational category with the rest of the blue collar occupations.

\section{Psychosocial work environment}

Data regarding psychosocial job demands and control were obtained from the Swedish version of the Karasek demandcontrol questionnaire. Five items investigated demands and six items focused on job control. Each question had four frequency response categories ranging from "never" to "always". The internal reliability was studied using Cronbach's $\alpha$ ( 0.84 for job demands and 0.85 for job control). The external reliability was studied using $\kappa$ ( 0.90 for job demands and 0.93 for job control).

In the analysis we used a dichotomisation at the median scores to categorise persons into score above the median for work demands and control as "high" and below the median as "low" (median value for job demands was 11, for job control 14). Job strain was derived from the ratio between psychosocial job demands and control (job strain ratio).

\section{Statistical methods}

We used SPSS 10.0 for Windows in the statistical analysis. The mean and standard error of mean of self reported job control and job demands scores were calculated for each occupational category for cases and controls. Analysis of variance was used to test for significant differences in means. To adjust for potential confounding effects of the selected risk factors multiple logistic regression analysis was performed. Potential cofounders included in the models were factors age, socioeconomic status, arterial hypertension, smoking, and obesity. The adjusted OR along with their $95 \%$ CI for each risk factor relative to the reference category were assessed and the effect of the risk factors on the risk of myocardial infarction was evaluated.

\section{RESULTS}

Table 1 presents the distribution of occupational categories, age, and job characteristics among cases and controls. Cases and controls were similar according to their age. The mean values for job demands were lower in the cases' group. As the 7 th occupational category (craft and related trades workers) was quite large and distributed quite equally among cases

Table 1 Distribution of occupational categories, age, and job characteristics among cases and controls, age adjusted odds ratios and $95 \%$ confidence intervals

\begin{tabular}{|c|c|c|c|c|c|c|}
\hline & Cases & ( $n=203)$ & Controls & $(n=287)$ & Age adjusted & Odds ratio \\
\hline & Number & $\%$ & Number & $\%$ & OR & $95 \% \mathrm{Cl}$ \\
\hline \multicolumn{7}{|l|}{ Occupational categories } \\
\hline 0 Armed forces & - & - & 5 & 1.7 & - & - \\
\hline 1 Legislators, senior officials and managers & 30 & 14.8 & 27 & 9.4 & 1.93 & 1.07 to 3.50 \\
\hline 2 Professionals & 22 & 10.8 & 36 & 12.5 & 1.06 & 0.58 to 1.94 \\
\hline 3 Technicians and associate professionals & 15 & 7.4 & 18 & 6.3 & 1.42 & 0.67 to 3.01 \\
\hline 4 Clerks & 1 & 0.5 & 2 & 0.7 & - & - \\
\hline 5 Service, shop, and market sales workers & 2 & 1.0 & 6 & 2.1 & - & - \\
\hline 6 Skilled agricultural workers & 1 & 0.5 & - & - & - & - \\
\hline 7 Craft and related trades workers* & 73 & 36.0 & 127 & 44.3 & 1.0 & \\
\hline 8 Plant and machine operators and assemblers & 54 & 26.5 & 60 & 20.9 & 1.58 & 0.99 to 2.52 \\
\hline \multirow[t]{2}{*}{9 Elementary occupations } & 5 & 2.5 & 6 & 2.1 & 1.45 & 0.43 to 4.92 \\
\hline & Mean & SEM† & Mean & SEM† & & \\
\hline Age (y) & 53.9 & 0.53 & 52.2 & 0.49 & & \\
\hline Psychosocial work environment & & & & & & \\
\hline Job control (6-24) & 13.2 & 0.18 & 14.2 & 0.18 & & \\
\hline Job demands (5-20) & 10.6 & 0.16 & 11.3 & 0.12 & & \\
\hline Job strain $\ddagger$ & 0.82 & 0.01 & 0.83 & 0.01 & & \\
\hline
\end{tabular}


Table 2 Characteristics of psychosocial work environment by occupational categories among men with myocardial infarction and control subjects

\begin{tabular}{|c|c|c|c|}
\hline \multirow[b]{3}{*}{ Occupational categories } & \multirow{3}{*}{$\begin{array}{l}\text { Job demands } \\
\text { Mean } \\
\left(\text { SEM }^{*}\right)\end{array}$} & \multirow{3}{*}{$\begin{array}{l}\text { Job control } \\
\text { Mean } \\
\text { (SEM*) }\end{array}$} & \multirow{3}{*}{$\begin{array}{l}\text { Job strain } \dagger \\
\text { Mean } \\
\text { (SEM*) }\end{array}$} \\
\hline & & & \\
\hline & & & \\
\hline \multicolumn{4}{|l|}{ Men with MI } \\
\hline 1 Legislators, senior officials, and managers & $11.5(0.4)$ & $15.8(0.5)$ & $0.73(0.03)$ \\
\hline 2 Professionals & $10.3(0.5)$ & $14.2(0.6)$ & $0.73(0.03)$ \\
\hline 3 Technicians and associate professionals & $9.8(0.4)$ & $14.0(0.6)$ & $0.71(0.02)$ \\
\hline $4 \& 5$ Clerks, service, market sales workers & $10.3(1.3)$ & $10.7(1.5)$ & $0.98(0.09)$ \\
\hline 7 Craft and related trades workers & $10.3(0.2)$ & $12.6(0.3)$ & $0.84(0.03)$ \\
\hline 8 Plant and machine operators and assemblers & $10.9(0.3)$ & $12.4(0.3)$ & $0.89(0.02)$ \\
\hline 9 Elementary occupations & $9.6(1.6)$ & $10.8(0.8)$ & $0.90(1.16)$ \\
\hline $\mathrm{p}$ for trend & 0.05 & $<0.0001$ & 0.14 \\
\hline \multicolumn{4}{|l|}{ Controls } \\
\hline 1 Legislators, senior officials, and managers & $12.5(0.4)$ & $17.8(0.7)$ & $0.73(0.04)$ \\
\hline 2 Professionals & $11.1(0.3)$ & $15.4(0.5)$ & $0.76(0.04)$ \\
\hline 3 Technicians and associate professionals & $10.4(0.5)$ & $14.8(0.6)$ & $0.72(0.05)$ \\
\hline $4 \& 5$ Clerks, service, market sales workers & $11.1(0.6)$ & $13.5(1.4)$ & $0.89(0.10)$ \\
\hline 7 Craft and related trades workers & $11.4(0.2)$ & $13.7(0.3)$ & $0.87(0.02)$ \\
\hline 8 Plant and machine operators and assemblers & $10.9(0.2)$ & $13.3(0.3)$ & $0.84(0.02)$ \\
\hline 9 Elementary occupations & $9.5(0.8)$ & $9.7(0.8)$ & $1.00(0.08)$ \\
\hline $\mathrm{p}$ for trend & 0.05 & $<0.0001$ & 0.05 \\
\hline
\end{tabular}

and controls, it was chosen as referent category for further comparisons among occupational categories. The highest myocardial infarction risk groups were legislators, senior officials and managers (1st occupational category) and plant and machine operators and assemblers (8th occupational category) as compared with craft and related trades workers (7th occupational category). The age adjusted odds ratio estimates did not change substantially after adjustment for standard risk factors, for example, smoking, arterial hypertension, and obesity.

The mean values of job demands and job strain were similar in the cases and controls among the occupational categories (table 2). Therefore, in future calculations only results for job control are presented. The age adjusted odds ratio for high job demands was 0.65 (95\% CI 0.45 to 0.94 ), for job strain 1.08 (95\% CI 0.75 to 1.55$)$.

Low job control was associated with an increased myocardial infarction risk in the population of 25-64 year old Kaunas men (age adjusted odds ratio was 1.99). Adjusting for socieconomic status increased the risk to 2.68, and for cardiovascular risk factors decreased the magnitude of the association to 2.31 (table 3).

Table 4 presents the effect of low job control for all occupational categories. The 0th, 4th, 5th, 6th, and 9th occupational categories were excluded from the analysis because of the small number of subjects. The odds ratio estimates for low job control were significantly increased in the high risk occupational categories (1st, 8th) as well as in non-increased myocardial infarction risk (2nd, 3rd, 7th), for example, the odds ratios were similar. The adjustment for socioeconomic status increased the effect of low job control for all the occupational categories, further adjustment for standard risk factors attenuated odds ratio estimates to insignificant for the 2nd and 3rd occupational categories.

\section{DISCUSSION}

We conducted a case-control study among able bodied men in Kaunas using the short Swedish version of the demandcontrol questionnaire to show the effect of psychosocial factors at work on myocardial infarction risk for different occupational categories. The main finding of our study was that low job control independently had a significant effect on myocardial infarction risk in all the occupational categories of Kaunas men, Lithuania, a country in a transition market economy.

Some possible limitations of the study, which include myocardial infarction diagnostic bias, selection, coding, and recall bias could occur in this study. The method of finding cases and case ascertainment in this study was comparable to that of myocardial infarction registers set up in accordance with principles adopted in the WHO MONICA programme. Nevertheless, there were several sources of errors that may have caused a misclassification of the clinical diagnosis. These errors include diagnostic errors in silent cases, coding errors or other clerical errors in data recording. However, this type of misclassification is probably unrelated to occupation.

Recall bias could occur in the self reported information on the psychosocial work environment as well. One potential source of recall bias is the fact that the subjects in the case group were interviewed after the myocardial infarction. Such bias has been labelled search for meaning. A large Swedish case-control study showed, however, ${ }^{6}$ that search for meaning is not a problem for job control in this type of study of first myocardial infarction. Accordingly in our study such

Table 3 Adjusted odds ratios and 95\% confidence intervals for low job control and myocardial infarction risk in 25-64 year old men in Kaunas

\begin{tabular}{|c|c|c|c|c|c|c|c|c|}
\hline \multirow[b]{2}{*}{ Job control* } & \multicolumn{2}{|c|}{ Model I } & \multicolumn{2}{|c|}{ Model II } & \multicolumn{2}{|c|}{ Model III } & \multicolumn{2}{|c|}{ Model IV } \\
\hline & OR & $95 \% \mathrm{Cl}$ & OR & $95 \% \mathrm{Cl}$ & OR & $95 \% \mathrm{Cl}$ & OR & $95 \% \mathrm{Cl}$ \\
\hline $\begin{array}{l}\text { High } \\
\text { Low }\end{array}$ & $\begin{array}{l}1.0 \\
1.99\end{array}$ & 1.36 to 2.92 & $\begin{array}{l}1.0 \\
1.68\end{array}$ & 1.12 to 2.53 & $\begin{array}{l}1.0 \\
2.68\end{array}$ & 1.68 to 4.28 & $\begin{array}{l}1.0 \\
2.31\end{array}$ & 1.42 to 3.78 \\
\hline
\end{tabular}

*Dichotomisation at the median scores. Model I; adjusted for age. Model II; adjusted for age, smoking, arterial hypertension, obesity. Model III; adjusted for age, socioeconomic status. Model IV; adjusted for age, socioeconomic status, smoking, arterial hypertension, obesity. 
Table 4 Adjusted odds ratios and $95 \%$ confidence intervals of first myocardial infarction by low job control for the occupational categories

\begin{tabular}{|c|c|c|c|c|c|c|c|c|}
\hline \multirow[b]{2}{*}{ ISCO*categories } & \multicolumn{2}{|c|}{ Model I } & \multicolumn{2}{|c|}{ Model II } & \multicolumn{2}{|c|}{ Model III } & \multicolumn{2}{|c|}{ Model IV } \\
\hline & OR & $95 \% \mathrm{Cl}$ & OR & $95 \% \mathrm{Cl}$ & OR & $95 \% \mathrm{Cl}$ & OR & $95 \% \mathrm{Cl}$ \\
\hline Ist ISCO category & 2.61 & 1.70 to 4.01 & 2.23 & 1.42 to 3.50 & 2.78 & 1.31 to 5.93 & 2.02 & 0.89 to 4.52 \\
\hline 2nd ISCO category & 2.01 & 1.35 to 2.98 & 1.70 & 1.12 to 2.58 & 2.23 & 1.09 to 4.56 & 1.60 & 0.75 to 3.44 \\
\hline 3rd ISCO category & 2.00 & 1.37 to 2.94 & 1.69 & 1.12 to 2.54 & 2.39 & 1.13 to 5.06 & 1.78 & 0.80 to 3.97 \\
\hline 7th ISCO category & 2.17 & 1.46 to 3.21 & 1.81 & 1.92 to 2.74 & 2.72 & 1.51 to 4.90 & 2.48 & 1.34 to 4.57 \\
\hline 8th ISCO category & 1.88 & 1.26 to 2.79 & 1.63 & 1.07 to 2.49 & 2.72 & 1.56 to 4.89 & 2.50 & 1.35 to 4.60 \\
\hline All employed men & 1.99 & 1.36 to 2.92 & 1.68 & 1.12 to 2.53 & 2.59 & 1.66 to 4.04 & 2.17 & 1.36 to 3.46 \\
\hline
\end{tabular}

Model I; adjusted for age; Model II; adjusted for age, smoking, arterial hypertension, obesity. Model III; adjusted for age and socioeconomic status. Model IV adjusted for age, socioeconomic status, smoking, arterial hypertension, obesity. * ISCO International Standard Classification of Occupations 1991 , Geneva. 1st ISCO category-legislators, senior officials, and managers. 2nd ISCO category-professionals. 3rd ISCO category-technicians and associate professionals. 7th ISCO category-craft and related trades workers. 8th ISCO category-plant and machine operators and assemblers.

recall bias is unlikely to have had any effect on the findings for job control. If there would be any effect at all it would be in the direction of inflated findings in the direction of high demands-increased risk. But the findings were in the opposite direction in this study.

The cardinal effect of low job control on increased risk of coronary heart disease and myocardial infarction has been revealed in the epidemiological studies in the countries of welfare $e^{4-812}{ }^{14}$ as well in the country of the previous Soviet Bloc. ${ }^{10}$ Although the recent results from Whitehall II study on British civil servants indicated that job strain, high job demands, and, to some extent, low decision latitude are associated with an increased risk of coronary heart disease. ${ }^{17}$ The 25 year follow up of the Chicago Western Electric study also found both job control and job demand negatively associated with coronary heart disease mortality. ${ }^{18}$ Our results indicated that low job control independently had a significant effect on myocardial infarction risk in the 25-64 year old male population even after adjustment for socioeconomic status and standard risk factors as smoking, arterial hypertension, obesity. Job strain remains a risk factor in the more "Western" countries, whereas job control is a more important risk factor in the transition countries.

In Western countries men in lower social positions are at increased myocardial infarction risk. ${ }^{12}$ The results from a case-control study in Kaunas, Lithuanian, a country in a transition market economy, did not support this point. ${ }^{15}$ Although a large cross-sectional study among managers in Germany has concluded that managers showed somewhat lower cardiovascular risk levels than did other professional groups $^{19}$ and there is some evidence that managerial stress could be moderated by a high level of job control, ${ }^{20}$ our study revealed that lst occupational category (legislators, senior officials, and managers) were at increased myocardial infarction risk even after adjustment for standard risk factors. The possible explanation could be that the transition causes enormous problems for the administrators. The necessity to learn something about information technology and new ways of management on the one hand and the difficulties to do it on the other hand might be a cause of profound feeling of lack of control.

The second occupational category of the increased myocardial infarction risk was the 8th (plant and machine operators and assemblers). It is well known that repetitive work holds low control of work pace and that level of epinephrine in assembly line workers is increased. ${ }^{21}$

The main objective of our article was to evaluate the effect of low job control on myocardial infarction risk for the occupational categories in Kaunas men. We carried out an epidemiological case-control study among the able bodied male population in Kaunas and showed that low job control had significant effect for the occupational categories of increased myocardial infarction risk as well as for the nonincreased risk, for example, there was no effect modification from employment status.

In Western societies there is evidence that the risk of myocardial infarction is higher in lower social positions and that a substantial contribution to the socioeconomic gradient was from low job control. ${ }^{13}$ This point of view was confirmed in the Stockholm heart epidemiology program (SHEEP) in Sweden indicating that low job control could explain 30\% of the increased myocardial infarction risk among manual workers. ${ }^{12}$ Job control was positively related to education and social group in the cross-sectional study in a random population sample in Gothenborg, Sweden. ${ }^{22}$ The British Whitehall II study (prospective cohort) on civil servants indicated that adjusting for employment grade somewhat reduced the strength of the association between job control and coronary heart disease. ${ }^{17}$ Wide ranges of clerical occupations do not represent all the occupational categories, especially blue collar. The Danish case-control study among men in all occupations, white collar as well as blue collar, indicated that the association between socioeconomic status and myocardial infarction risk could not be explained by the psychosocial factors at work. ${ }^{14}$

The comparative cross sectional Lithuanian-Swedish study showed that in both countries the unfavourable psychosocial work characteristics have been more prevalent in low social classes. ${ }^{16}$ According to our results, in two occupational categories of the increased myocardial infarction risk low job control plays the essential part, for example, for the "highest" - lst occupational category (legislators, senior, officials, and managers) and "not the lowest"-8th category (plant and machine operators and assemblers). Though low job control is relevant for the rest of the occupational

\section{Key points}

- Low job control is the risk factor for the first myocardial infarction in the 25-64 year old male population in Kaunas, Lithuania, a country in a transition market economy.

- Low job control plays the essential part in two occupational categories of the increased myocardial infarction risk: 1st-legislators, senior officials, and managers, 8th-plant and machine operators and assemblers.

- Although low job control is not more distinctive for low social classes in Kaunas, it seems an important myocardial infarction risk factor for all the occupational categories. 


\section{Policy implications}

- Strategies for improving job control at the workplace would lead to decreased effect of low job control on first myocardial infarction risk.

- The methods of increasing job control should be implemented not only in welfare societies, but in the countries after transition as well.

categories as 2nd (professionals), 3rd (technicians and associate professionals), and 7th (craft and related trades workers). Thus, we can conclude that low job control is not more distinctive for low social classes in Kaunas, the second largest city of Lithuania, it seems an important first time myocardial infarction risk factor for all the occupational categories. As the intervention studies showed that increase in job control over three years was associated with decrease in cigarette smoking ${ }^{23}$ and decreased the risk of coronary heart disease, ${ }^{7}$ this suggests that policy implications should be directed towards improving the working climate by means of increasing job control.

\section{ACKNOWLEDGEMENTS}

We thank V Dulskiene, D Garsviene, K Jankauskiene for data collection process and J Medzioniene for the statistical analysis.

\section{Authors' affiliations}

V Malinauskiene, A Azaraviciene, Laboratory of Environmental Epidemiology, Institute of Cardiology Kaunas University of Medicine, Kaunas, Lithuania

T Theorell, National Institute for Psychosocial Medicine, Stockholm, Sweden

R Grazuleviciene, Department of Environmental Sciences, Vytautas Magnus University, Kaunas, Lithuania

Funding: the project has been sponsored by the Nordic Council of Ministers Information Office in Lithuania (project code DVP/09).

Conflicts of interest: none declared.

\section{REFERENCES}

1 Karasek R, Brisson C, Kawamaki N. The job content questionnaire (JCQ): an instrument for internationally comparative assessments of psychosocial job characterstics. J Occup Health Psychol 1998;3:322-55.

2 Theorell T. The demand-control-support model for studying health in relation to the work environment: an interactive model. In: Orth-Gomér K, Schneiderman N, eds. Behavioral medicine. Approaches to cardiovascular disease prevention. Mahwah, NJ: Lawrence Erlbaum, 1995:69-95.
3 Hammar N, Alfredsson L, Theorell T. Job characteristics and the incidence of myocardial infarction. Int J Epidemiol 1994;23:277-84.

4 Steenland K, Johnson J, Nowlin SA. follow-up study of job strain and heart disease among males in the NHANES1 population. Am J Ind Med 1997;31:256-9.

5 Hammar N, Alfredsson L, Johnson JV. Job strain, social support at work, and incidence of myocardial infarction. Occup Environ Med 1998;55:548-53.

6 Theorell T, Tsutsumi A, Hallquist J, et al. Decision latitude, job strain and myocardial infarction: a study of working men in Stockholm. Am J Public Health 1998;88:382-8.

7 Bosma H, Marmot MG, Hemingway $\mathrm{H}$, et al. Low job control and risk of coronary heart disease in Whitehall II (prospective cohort) study. BMJ 1997;314:558-65.

8 Bosma H, Stansfeld SA, Marmot MG. Job control, personal characteristics, and heart disease. J Occup Health Psychol 1998;3:402-9.

9 Pikhart H, Bobak M, Siegrist A, et al. Psychosocial work characteristics and self rated health in four post-communist countries. J Epidemiol Community Health 2001;55:624-30.

10 Bobak M, Hertzman C, Skodova Z, et al. Association between psychosocial factors at work and nonfatal myocardial infarction in a population-based case-control study in Czech men. Epidemiology 1998;9:43-7.

11 Kristenson M, Kucinskiene Z, Bergdahl B, et al. Increased psychosocial strain in Lithuanian versus Swedish men: the LiVicordia study. Psychosom Med 1998:60:277-82.

12 Hallqvist J, Diderichsen F, Theorell T, et al. Is the effect of job strain on myocardial infarction risk due to interaction between high psychological demands and low decision latitude? Results from Stockholm heart epidemiology program (SHEEP). Soc Sci Med 1998;46:1405-15.

13 Marmot MG, Bosma H, Hemingway H, et al. Contribution of job control and other risk factors to social variations in coronary heart disease incidence. Lancet 1997; 350:235-9.

14 Netterstrøm B, Finn EN, Kristensen TS, et al. Relation between job strain and myocardial infarction: a case-control study. Occup Environ Med 1999;56:339-42.

15 Malinauskiene V, Grazuleviciene R, Nieuwenhuijsen M, et al. Myocardial infarction risk and occupational categories in Kaunas 25-64 year old men. Occup Environ Med 2002;59:745-50.

16 Kristenson M, Kucinskiene Z, Bergdahl B, et al. Risk factors for coronary heart disease in different socioeconomic groups of Lithuania and Sweden-the LiVicordia study. Scand J Public Health 2001;29:140-50.

17 Kuper H, Marmot M. Job strain, job demands, decision latitude, and risk for coronary heart disease within the Whitehall II study. J Epidemiol Community Health 2003;57:147-53.

18 Alterman T, Shekelle RB, Vernon SW, et al. Decision latitude, psychological demands, job strain, and coronary heart disease in the Western Electric Study. Am J Epidemiol 1994; 139:620-7.

19 Ketner M, Cire L, Scholl J. Psychosocial and clinical risk factor profiles in managers. Int Arch Occup Environ Health 2000;73(suppl):S33-40.

20 Theorell T, Karasek RA. The demand-control-support model and CVD. In: Schnall PL, Belkic K, Landsbergis P, Baker D, eds. Occupational medicine. The workplace and cardiovascular disease. Philadelphia: Hanley and Belfus, 2000:78-83.

21 Lundberg $U$, Johansson $G$. Stress and health risks in repetitive work and supervisory monitoring work. In: Backs R, Boucsein W, eds. Engineering psychophysiology: issues and applications. Hillsdale, NJ: Lawrence Erlbaum, 2000:339-59.

22 Jonsson D, Rosengren A, Dotevall A, et al. Job control, job demands and social support at work in relation to cardiovascular risk factors in MONICA 1995, Goteborg. J Cardiovasc Risk 1999;6:379-85.

23 Landsbergis PA, Schnall PL, Deitz DK, et al. Job strain and health behaviors: results from a prospective study. Am J Health Promot $1998 ; 12: 237-45$. 


\section{PostScript}

LETTERS

If you have a burning desire to respond to a paper published in the JECH, why not make use of our "rapid response" option?

Log on to our website (www.jech.com) find the paper that interests you, and send your response via email by clicking on the "eletters" option in the box at the top right hand corner

Providing it isn't libellous or obscene, it will be posted within seven days. You can retrieve it by clicking on "read eletters" on our homepage.

The editors will decide as before whether to also publish it in a future paper issue.

\section{No place for modesty}

"A leader is best when people barely know he exists, not so good when people obey and acclaim him, worse when they despise him.. But of a good leader who talks little when his work is done, his aim fulfilled, they will say, "We did it ourselves."

Clearly John Ashton's aphorism mirrors Lao Tzu's thoughts on leadership, and is thus hard to argue against. ${ }^{1}$ However, I think public health practitioners should indeed be "bothered... if we don't get the credit for our own ideas." It is precisely this self effacing stance that has led to the current situation where public health is grossly undervalued and under-resourced. It is hard enough trying to promote a negative-the disease outbreak that didn't happen-we only make it worse for ourselves if we allow others to claim responsibility for all the visible successes.

Why should public health practitioners be employed if the successes are due to the "exertions" of politicians and generic bureaucrats? It is time that we assembled the evidence of our many successes and market public health and its practitioners aggressively. We need to attract the attention of those who procure sickness services at ever increasing expense and show them the folly of neglecting the protectors, promoters, and the preventers. Time to dispense with the bushel and let our lights shine!

C R Douglas

Australasian Faculty of Public Health Medicine PO Box S1296 Perth, WA 6845, Australia charles.douglas@health.wa.gov.au

\section{Reference}

Ashton JR. "Success has 100 parents, failure is an orphan". J Epidemiol Community Health 2003;57:646

\section{Standardised QALYs and DALYs are more understandable, avoid misleading units of measurement, and permit comparisons}

QALYs and DALYs combine years of life and quality of life in a single measure. ${ }^{1-3}$ In Arnesen and Nord's words: "DALYs and QALYs are complementary concepts. QALYs are years of healthy life lived; DALYs are years of healthy life lost. Both approaches multiply the number of years ( $\mathrm{x}$ axis) by the quality of those years (y axis). QALYs use "utility weights" of health states; DALYs use "disability weights" to reflect the burden of the same states. For example, if the utility of deafness is 0.67 , the disability weight of deafness is $1-0.67=0.33$. Disregarding age weighting and discounting, and assuming lifetime expectancy of 80 years, a deaf man living 50 years represents $0.67 \times 50=33.5$ QALYs gained and $0.33 \times 50+1.0 \times(80-50)$ $=46.5$ DALYs lost". ${ }^{\prime 2}$ We can see that $33.5+46.5=80.0$ - that is, QALYs+DALYs = lifetime expectancy.

If we would like to be more accurate, we had to put QALYs $=0.67 \times 50 y=33.5 y$ and DALYs $=0.33 \times 50 y+1.0 \times(80 y-30 y)=46.5 y$. This means that the unit of measurement of QALYs and DALYs is years (y). As y is the unit of measurement of lifetime, using the same unit for the product "lifetime $\times$ lifequality" is confusing

Saying that quality is rated on a scale from 0 to 1 , we, in fact, have implicitly transformed the real but unknown scale of quality into a standard scale, where 0 denotes no quality at all and 1 the $100 \%$ of quality expected (lifequality expectancy). Therefore, QALYs and DALYs, combining actual years (axis $\mathrm{x}$ ) and dimensionless quality (axis y), are, in fact, semi-standardised measures.

We can do the same with the dimension of time, assigning 0 to birth and 1 to lifetime expectancy. Continuing the example above, the dimensionless $\mathrm{l}$ is assigned to $80 \mathrm{y}$, the dimensionless 0.625 to $50 \mathrm{y}(50 \mathrm{y} / 80 \mathrm{y})$ and the dimensionless 0.375 to $30 \mathrm{y}(30 \mathrm{y} / 80 \mathrm{y})$. Thus, fully standardised QALYs $=$ SQALYs $=0.67 \times$ $0.625=0.41875$, and fully standardised DALYs $=$ SDALYs $=0.33 \times 0.625+1.00 \times 0.375$ $=0.58125$; that is, $41.875 \%$ of the life expected to be lived was actually lived and $58.125 \%$ was lost. Again SQALYs+SDALYs = $1=100 \%=$ life expectancy

These transformed to fully dimensionless standardised measures seem to be more understandable: SQALYs are the percentage of life lived, and SDALYs the percentage of life lost; as their sum equals 1, they are complementary. They do not measure life as lifetime; therefore they are not misleading. And thirdly they permit comparisons between countries, nations, sub-nations, etc, with different lifetime expectancy.

In contrast, we could of course unstandardise both axes, by assigning lifequality its real scale, but it remains to be discovered.

Department of Hygiene and Epidemiology, Medical School, University of loannina, 45110 loannina, Greece; idimolia@cc.uoi.gr

doi: 10.1136/jech.2003.014167

\section{References}

1 Murray CJL, Lopez AD. Global burden of disease study, Lancet 1997:349:1269-76, 1347-52, 1436-42, 1498-504.

2 Arnesen T, Nord E. The value of DALY life: problems with ethics and validity of disability adjusted life years. BMJ 1999;319:1423-5.
3 Gold MR, Stevenson D, Fryback DG. HALYs and QALYs and DALYs, oh my: similarities and differences in summary measures of population health. Annu Rev Public Health 2002;23: 115-34

\section{Previous trials of dissemination were identified}

Morrison et al examine the effect on ques tionnaire response of feeding back research findings to participants. ${ }^{1}$ As authors of the systematic review ${ }^{2}$ cited in their paper we would like to point out that we had in fact identified eight such randomised trials. ${ }^{3-10}$ The broad strategy under which these trials had been classified in our review was "nonmonetary incentives". We are currently updating our systematic review and have recently extended the search of databases to the beginning of 2003 and have contacted the authors of potentially eligible trials. A further two trials ${ }^{11} 12$ have been identified and the total of 10 trials have also been classified under the new strategy called "offer of research findings". These trials include a total of 13642 participants. When the results of these trials are pooled in a random effects meta analysis the odds ratio for response with research findings is 0.92 (95\% CI 0.75 to 1.11). Despite omitting to refer to these previous trials, Morrison et al were justified in conducting their trial: few of such trials have been health related and none has examined the effect of this intervention when participants are being resurveyed. However, even with the inclusion of their new trial in our systematic review, uncertainty about the effect of dissemination of research findings on questionnaire response remains.

The update to our systematic review now includes a total of 372 trials of methods to influence response to postal questionnaires, classified under 98 strategies. Although many conclusions remain unchanged our updated review presents the definitive account of the evidence for which strategies may be used to improve response to postal questionnaires. The updated review will appear in the Cochrane Library later this year.

P Edwards, R Cooper Department of Epidemiology and Population Health London Schoo of Hygiene and Tropical Medicine London, UK

Correspondence to: Mr P Edwards, LSHTM, 49-51 Bedford Square, London WC1B3DP, UK phil.edwards@|shtm.ac.uk

\section{References}

1 Morrison DS, Thomson H, Petticrew M. Effects of disseminating research findings on response rates in a community survey: a randomised controlled trial. J Epidemiol Community Health 2003;57:536-7

2 Edwards $\mathbf{P}$, Roberts I, Clarke $M$, et al. Increasing response rates to postal questionnaires: systematic review. BMJ 2002:324:1183-5.

3 Dommeyer CJ. Does response to an offer of mail survey results interact with questionnaire interest? Journal of the Market Research Society 1985; 27:27-38.

4 Dommeyer CJ. Offering mail survey results in a lift letter. Journal of the Market Research Society 1989:31:399-408

5 Glisan G, Grimm JL. Improving response rate in an industrial setting: will traditional variables 
work? Southern Marketing Association Proc 1982;20:265-8.

6 Green KE, Kvidahl RF. Personalization and offers of results: effects on response rates. Journal of Experimental Education 1989;57:263-70.

7 Jobber D, Sanderson S. The effect of two variables on industrial mail survey returns. Industrial Marketing Management 1985; 14:119-21.

8 Kerin RA, Barry TE, Dubinsky AJ, et al. Offer of results and mail survey response from a commercial population: a test of Gouldner's norm of reciprocity. Proceeding of the American Institute of Decision Sciences 1981:283-5.

9 Mullner RM, Levy PS, Byre CS, et al. Effects of characteristics of the survey instrument on response rates to a mail survey of community hospitals. Public Health Rep 1982;97:465-9.

10 Powers DE, Alderman DL. Feedback as an incentive for responding to a mail questionnaire. Research in Higher Education 1982;17: 207-11.

11 Thistlethwaite PC. The impact of selected mail response enhancement techniques on surveys of the mature market: some new evidence. Journal of Professional Services Marketing 1993:8:269-76.

12 Wiseman F. Methodological bias in public opinion surveys. Public Opinion Quarterly 1972;36:105-8.

\section{BOOK REVIEWS}

\section{Terrorism and public health: a balanced approach to strengthening systems and protecting the public}

Barry S Levy, Victor W Sidel, editors. (Pp 377; £35.00). Oxford University Press, New York 2003. ISBN 0-19-515834-2

The preface states: "we believe this is the firs book that addresses terrorism from a public health perspective that is both comprehensive and balanced" (page xi). To a large extent, the book fulfils this promise, offering an informative, up to date, and highly readable summary of a broad range of public health issues that interface with the problem of international terrorism.

Part I has an introductory chapter followed by seven chapters examining public health challenges emerging after the September 11 th attacks. Four of these chapters summarise events in New York City, one covers the anthrax epidemic, one covers public health problems in war strapped Afghanistan, and one chapter offers an erudite and much needed account of the prospects for educating, informing, and mobilising the public.
Much of the material in part I is based on firsthand experience, and it is packed with information and insights that are unlikely to be found elsewhere. Part II covers conventional, biological, chemical, nuclear, and radiological terrorist weapons. Attention often focuses on arms control and its political underpinnings, but clinical aspects are also covered (though in too little detail to provide an important reference for clinicians). Part III addresses terrorism related "challenges and opportunities," with chapters aimed at public health systems, epidemiology, therapeutic interventions, research, environmental protection, civil liberties, roots of terrorism, and the promotion of international law. The comprehensiveness of the text suffers slightly from the lack of attention to methods of decontamination, structure and function of Incident Command Systems, and the coordination of disaster services under the Federal Emergency Management Agency.

The text is well "balanced" in the manner intended by the authors in so far as it nicely situates the need for terrorism prevention and response capabilities within the context of other, potentially competing public health needs, and it balances these needs against the imperative to avoid "inappropriate or hazardous responses to threats of future terrorism." On the other hand, there is little balance between competing viewpoints on ethical or policy issues. The book is structured by liberal cosmopolitan ideology-including numerous attacks on the Bush administration-with no attempt to fairly represent the range of credible, diverging opinions about the nature of justice or the intricacies of international collaboration and arms control.

G Trotter

\section{Dawning answers: how the HIV/ AIDS epidemic has helped to strengthen public health}

Ronald O Valdiserri, editor. (Pp 209; £29.92). Oxford University Press, 2003. ISBN 0-19514740-5

The HIV epidemic is still a great threat to public health, and the complexity of the infection regarding both biological and social aspects has challenged our skills to prevent its spread. The book presents a historica analysis to inform current policy development and to forecast the future, and describes some very important lessons learned during more than two decades with the HIV epidemic.
HIV has influenced the development and understanding of the use of multiple surveillance methods, integrated case based and behavioural surveillance, active collaboration between different public health stakeholders, and confidentiality and anonymity have become important issues.

Although sex may well be the most pleasurable human activity it is also very tabooed. The HIV risk reduction thus entails difficult behaviour changes, and the involvement of community members in this public health activity has become crucial. The adoption of "grey area" behaviours among at risk populations has led to the need for structural and individual level intervention. The HIV epidemic has shown the necessity of understanding surveillance data in their social context, for example, sex for drug. At the same time the "All or nothing" thinking opened to the principle of harm reduction.

The HIV epidemic has shown the importance of translating research results into active intervention and routine service delivery. HIV has had an impact on the organisation of prevention and care services and the public health planners are urged to consider the entire healthcare system, using all data available. Legal aspects and ethical issues, such as human rights, especially in relation to testing policy, named reporting and partner notification are very well discussed in the book.

The nine chapters are mainly dealing with the situation in the USA, however, the history in most western countries is similar and the book is absolutely worth reading for those interested in public health and in the HIV/ AIDS epidemic and policy. The public health challenges from infection diseases never stop.

E Smith

\section{CORRECTIONS}

doi: 10.1136/jech.2003.010553corr

An editorial error occurred in this paper by Dr Malinauskiene and others (2004;58:1315). The affiliation of $\mathrm{Dr} \mathrm{R}$ Malinauskas is Department of Psychology, Lithuanian Academy of Physical Education (this was omitted from the article).

doi: 10.1136/jech.2003.009589corr

An editorial error occurred in this paper by Drs Mindell and Joffe $(2004 ; 58: 103-13)$. In table 3, the age group for the first row of IHD admissions should be 0-64 (not 0-4). 